\title{
VALIDITAS DAN RELIABILITAS TES MELENGKAPI WACANA PADA PENELITIAN PRAGMATIK BAHASA ANTARA (INTERLANGUAGE PRAGMATICS)
}

\author{
Bayu Aryanto, Syamsul Hadi, Tatang Hariri \\ bayu.aryanto@mail.ugm.ac.id. \\ Universitas Gadjah Mada
}

\begin{abstract}
This article is intended to provide insight to researchers who are still doubtful about the validity and reliability of one of the data collection methodologies, namely the method of discourse completion test in general pragmatic research and interlanguage pragmatics. The literature review was used in the preparation of this article to get the comprehensive picture of the completion discourse test. One of the results is that data collection methods using completion discourse test have advantages and disadvantages. One drawback is that the authenticity of the data and the limitations on the data quality obtained from an informant or respondent, even in certain studies, is judged to not be able to capture sufficiently good data. However, this method is a very good method to find stereotype data because researchers can obtain abundant data in sufficient quantities by this method. In addition, this completion discourse test is very effective in the language study in the cross-cultural domain. This method can be used to capture data in two or more languages with different cultural backgrounds as Blum-Kulka and Olshtain did (in 1984). The control of research variables by using the completion discourse test is considered better because one of the research variables in pragmatic studies is the context of conversation which is very dynamic so that there needs to be controlled. Controlling this research variable is expected to be able to make conclusions that are more conical answer for the research problem.
\end{abstract}

Keywords: discourse completion test, interlanguage pragmatics, research variable control

Pada penelitian bahasa terutama pada penelitian pragmatik, paling tidak ada dua jenis data dilihat dari bagaimana data itu diperoleh. Jenis data yang pertama yaitu data otentik, merupakan data yang diperoleh dengan cara "natural". Dalam penelitian pragmatik, jenis data ini biasanya diambil dengan cara observasi terhadap penutur sebagai subjek penelitian, tanpa campur tangan peneliti atau pemancing data. Tugas peneliti lebih terfokus pada aktivitas dokumentasi data, tanpa si penutur mengetahui bahwa dirinya sedang diobservasi. Interaksi "alami” antarpeserta tutur merupakan ciri 
Bayu Aryanto, Syamsul Hadi, Tatang Hariri, Validitas dan Reliabilitas Tes Melengkapi Wacana pada Penelitian Pragmatik Bahasa Antara (Interlanguage Pragmatics)

khas dalam metode pengumpulan data ini. Dengan kata lain, pendekatan yang digunakan merupakan pendekatan etnografi.

Di lain sisi, metode pengumpulan data dengan cara memberikan tes melengkapi wacana (DCT: discourse completion test), tidak jarang dilabeli sebagai metode pengumpulan data yang akan menghasilkan data yang "tidak "otentik", data "tidak alami”, data yang "tidak sesuai dengan perilaku penutur" karena tidak merefleksikan perilaku tindak tutur mereka dalam kehidupan nyata.

Namun demikian, kenyataannya DCT digunakan hingga saat ini oleh sebagian besar peneliti dalam kajian pragmatik, terutama pragmatik lintas rahasa dan pragmatik bahasa antara. Kemudian, sejauh mana reliabiliitas dan validitas DCT sebagai instrumen pengumpulan data? Dalam artikel ini, penulis ingin memberikan gambaran sejauh mana DCT dapat dijadikan sebagai salah satu metode pengumpulan data yang bisa dipertanggungjawabkan validitas dan reliabilitasnya secara ilmiah dalam kajian pragmatik. Penulis menggunakan kajian pustaka dari berbagai sumber, baik berupa artikel hasil penelitian maupun kajian teoretis yang menggunakan DCT sebagai instrumen pengumpulan datanya, baik secara tulisan (written-DCT) maupun lisan (oral-DCT)..

\section{KAJIAN TEORETIS}

Ada tiga pendekatan dalam penelitian bahasa berdasarkan pada lokasi pengambilan data, yaitu armchair, field method (metode lapangan), dan laboratory linguists (Clark-Bangerter. 2004: 25). Ketiga istilah tersebut dimunculkan oleh ClarkBangerter dalam sebuah artikelnya berjudul "Changing Ideas About Reference" yang dikumpulkan dalam sebuah buku kumpulan artikel "Experimental Pragmatics" (eds. Noveck-Sperber, 2004: 25-49).

It has been investigated largely by three methods - intuition, experiment and observation. With intuitions, you imagine examples of language used in this or that situation and ask yourself whether they are grammatical or ungrammatical, natural or unnatural, appropriate or inappropriate. This was 
Searle's method. With experiments, you invite people into the laboratory, induce them to produce, comprehend or judge samples of language, and measure their reactions. With observations, you note what people say or write as they go about their daily business. We will name these methods by their characteristic locations: armchair, laboratory and field.

Armchair method, bukan merupakan metode pengambilan data bahasa dengan pendekatan aktual. Metode ini berangkat dari pendekatan filosofis, membuat refleksi terhadap penggunaan bahasa. Ada dua jenis pendekatannya yaitu, pendekatan filosofis, yaitu pendekatan yang menggunakan intuisi dan introspeksi peneliti dalam analisisnya; dan pendekatan wawancara untuk memperoleh opini maupun variasi bahasa dari penutur bahasa tersebut (Jucker, 2009:1615).

Laboratory method, peneliti menggunakan teknik-teknis elisitasi data terhadap penutur agar memproduksi tuturan yang diinginkan oleh peneliti. Kerjasama informan sangat dibutuhkan dalam metode ini karena peneliti akan menggunakan instrument pemancing baik berupa konteks percakapan atau tuturan tertentu, baik tertulis maupun lisan. Selanjutnya informan diminta untuk memproduksi tuturan, baik verbal maupun nonverbal yang sesuai dengan konteks atau tuturan yang diberikan peneliti. (Jucker, 2009:1618). Ada dua teknik pengambilan datanya, yaitu tes melengkapi wacana (discourse completion test/ task) dan main peran (role play).

Ada dua kelompok besar DCT jika dilihat dari bagaimana DCT itu direspon oleh informan. Jenis pertama adalah W(written)-DCT (tes melengkapi wacanatertulis). Peneliti memberikan pemancing data (bisa berupa konteks atau tuturan) yang kemudian direspon oleh informan secara tertulis. Jenis yang kedua adalah O (oral)DCT. Peneliti memberikan konteks atau tuturan dalam bentuk tertulis maupun lisan, kemudian informan diminta untuk memberikan responnya secara lisan/oral. Respon informan tersebut direkam oleh peneliti dengan alat perekam audio atau audio-visual.

Kasper dan Dahl (1991) menyebutkan ada 5 tipe DCT berdasarkan bagaimana penyampaian "instrument pemancing datanya". (1) model klasik, model ini diawali dengan konteks percakapan, informan memberikan responnya dan ditutup oleh mitra tutur yang disebutkan dalam konteks percakapan (penutur pelibat); (2) diawali 
Bayu Aryanto, Syamsul Hadi, Tatang Hariri, Validitas dan Reliabilitas Tes Melengkapi Wacana pada Penelitian Pragmatik Bahasa Antara (Interlanguage Pragmatics)

konteks, diikut penutur pelibat dan ditutup dengan respon dari informan; (3) informan hanya diberi konteks dan diberi kebebasan yang lebih dalam merespon konteks (tanpa ada penutur pelibat). Informan diminta untuk merespon secara verbal; (4) hampir sama dengan model keempat, tetapi informan boleh menjawab secara nonverbal; (5) hampir sama dengan model ketiga tetapi konteksnya diberikan sangat detil, misall informasi tentang status informan dalam konteks tersebut, hubungannya dengan mitra tuturnya, tempat atau lokasi terjadinya tuturan, bahkan kondisi psikologis informan pun juga dijelaskan dalam konteks.

Field method, ciri khas metode ini adalah data diperoleh dari proses komunikasi para subjek penelitian yang tidak "dikendalikan" oleh peneliti. Dengan kata lain, subjek penelitian memproduksi data tanpa pemancing data atau keterlibatan peneliti dalam membuat sebuah situasi agar subjek penelitian memproduksi tuturan. Tuturan dalam hal ini bisa berwujud lisan maupun tulisan.

\section{METODE PENELITIAN}

Kajian komparatif terhadap literatur yang menggunakan DCT sebagai instrumen untuk mengumpulkan data digunakan untuk menyusun artikel ini. Penggunaan DCT baik yang tertulis maupun tidak tertulis (lisan) dalam berbagai penelitian bahasa pertama dan bahasa kedua. Pengamatan terhadap penggunaan DCT sebagai instrumen pengambilan data dan bagaimana realisasinya, serta implikasinya pada hasil penelitian, menjadi pokok pengamatan penyusunan artikel ini. Penelitian yang terkait dengan tuturan pujian dan respon pujian yang diteliti oleh Zohreh, et.all (2014); Emi (2011); Manami (1993); Asma (2013); dan Yi (2002) dijadikan data untuk dikaji hasil analisisnya.

\section{HASIL DAN PEMBAHASAN}

Tujuan penelitian ini adalah untuk memberikan argumentasi bahwa DCT merupakan alat satu intrumen pengumpulan data yang dapat dipertanggungjawabkan reliabilitas dan validitasnya. Oleh karena itu, kajian-kajian pustaka dilakukan untuk 
dapat melihat bagaimana DCT itu bekerja dan dapat dijadikan bukti reliabulitas dan validitas DCT dalam penelitian. Kajian pustaka yang pertama adalah sebuah penelitian yang fenomenal dalam lingkup kajian pragmatik ditulis oleh Blum-Kulka pada tahun 1982. Blum-Kulka menggunakan DCT secara masif pada proyek penelitian tentang realisasi tindak tutur permintaan (request) dan permintaan maaf (apologies) secara lintas budaya (The Cross Cultural Speech Act Realization Project) CCSARP). Blum-Kulka mencoba membandingkan tuturan permintaan dan permintaan maaf dari delapan bahasa (Australian English, American English, British English, Canadian French, Danish, German, Hebrew, Russian). Tujuan penelitian tersebut di antaranya untuk mengetahui pola realisasi tuturan permintaan dan permintaan maaf baik oleh penutur asli maupun bukan penutur asli, dan mengetahui persamaan dan perbedaan pola realisasi tuturan di antara bahasa-bahasa tersebut. Dengan kata lain, penelitiannya bertujuan untuk mencari pola realisasi tuturan dari tiap bahasa yang ditinjau secara pragmatik lintas bahasa (dalam hal ini informannya adalah penutur asli) dan ditinjau secara pragmatik bahasa antara (dalam hal ini informannya adalah penutur asing). Penelitian tersebut menggunakan written-DCT denga isi yang sama dan diterapkan selama proses pengambilan data terhadap objek bahasa yang berbeda-beda. Berikut contoh konteks yang dibuat oleh Blum-Kulka (1984: 211-212) untuk mengelisitasi data tuturan permintaan (request) dan permintaan maaf (apology).

Konteks permintaan

At a students' apartment

Larry, John's room-mate, had a party the night before and left the kitchen in a mess.

John : Larry, Ellen and Tom are coming for dinner tonight and I'll have to start cooking soon;

Larry : OK, I'll have a go at it right away

Konteks permintaan maaf

At the professor's office

A student has borrowed a book from her teacher, which she promised to return today. When meeting her teacher, however, she realizes that she forgot to bring it along.

Teacher : Miriam, I hope you bought the book I lent you.

Miriam

Teacher $\quad:$ OK, but please remember it next week. 
Bayu Aryanto, Syamsul Hadi, Tatang Hariri, Validitas dan Reliabilitas Tes Melengkapi Wacana pada Penelitian Pragmatik Bahasa Antara (Interlanguage Pragmatics)

Informan dari tiap bahasa sejumlah 400 orang dengan komposisi separuhnya adalah penutur asli dan sisanya adalah penutur asing. Berdasarkan data yang diperoleh, pola-pola realisasi tindak tutur permintaan dan permintaan maaf dapat terlihat di setiap bahasa yang ditelitinya.

Sejak saat itu, penggunaan DCT sebagai instrumen untuk mengumpulkan data pada kajian pragmatik (dan pragmatik bahasa antara) semakin luas. Berikut beberapa peneliti yang menggunakan DCT sebagai instrument pengumpulan data. Fukusawa (2011), menggunakan tes melengkapi wacana-lisan (oral discourse completion test) terhadap pembelajar bahasa Inggris orang Jepang untuk mengetahui bagaimana mereka memberikan tanggapan terhadap tindak tutur pujian yang dilakukan oleh penutur asli (orang Amerika). Para informan tersebut merupakan orang Jepang yang mengikuti program pelatihan bahasa Inggris selama lima bulan di Amerika. Salah satu tujuan penelitiannya adalah untuk menemukan apakah ada perubahan variasi ataupun strategi tanggapan tindak tutur pujian yang dilakukan oleh orang Jepang. Oleh karena itu, peneliti melakukan serangkaian tes lisan sebanyak tiga kali, yaitu sebelum informan berangkat ke Amerika, pada saat proses pelatihan, dan pascapelatihan bahasa Inggris.

Hirata (1993) menggunakan tes melengkapi wacana-tertulis (WDTC: written discourse completion test) dengan pengendalian variabel gender, hubungan antarpeserta tutur, dan usia dengan informannya adalah penutur asli bahasa Jepang. Tujuan penelitiannya adalah untuk memperoleh gambaran tindak tutur pujian dan tanggapannya dalam masayarakat Jepang, untuk kemudian digunakan sebagai bahan pertimbangan untuk pengembangan paedagogis.

Sejak kemunculannya, DCT tidak lepas dari kritikan terutama pada validitas dan realibilitas data yang dihasilkan. Berikut ringkasan dari beberapa peneliti yang menilai adanya kekurangan DCT (Manes dan Wolfson (1980), Kasper dan Dahl (1991), Cohen (1996) memaparkan beberapa kekurangan DCT, di antaranya: 
1) W (written)-DCT memberikan waktu berpikir informan sehingga berpotensi menimbulkan tuturan yang tidak natural.

2) Konteks yang diberikan dalam DCT terkadang menempatkan informan dalam sebuah konteks yang mungkin belum pernah mereka alami, sehingga informan merasa kesulitan untuk menemukan tuturan yang tepat.

3) Minimnya kesempatan informan untuk bernegosiasi, terutama pada WDCT (membuat hedges, repetisi, elaborasi).

4) Faktor ekstralinguistik tidak dapat terlihat terutama pada WDCT, seperti mimik muka, gestur, intonasi, tonal).

Di balik kekurangan DCT, terdapat pula keunggulan DCT, dan bahkan para pengkritik mengakui keunggulan DCT tersebut. Berikut beberapa keunggulan DCT:

1) Pengambilan jumlah data yang cukup banyak dalam waktu yang tidak terlalu lama. Umumnya penggunaan metode ini berkaitan dengan tujuan peneliti yaitu pencarian stereotype tuturan dari sebuah konteks percakapan. Dengan masifnya data yang bisa diperoleh, sehingga berpotensi diperoleh variasi data yang komprehensif.

2) Masifnya data yang bisa diperoleh, berpotensi dapat dibuat klasifikasi formula semantik dan strategi tuturan yang punya potensi muncul dalam realitas.

3) Pengendalian terhadap variabel penelitian seperti konteks, kriteria informan (umur, gender, kemampuan berbahasa asing, latar belakang Bahasa dan budaya). Dengan pengendalian variabel tersebut, akan memudahkan terhadap penarikan kesimpulan yang lebih fokus.

4) DCT dapat digunakan untuk penelitian ke dalam dua objek penelitian dengan latar belakang bahasa dan budaya yang berbeda. Misal, sebuah konteks dalam metode DCT digunakan untuk pengambilan sebuah penelitian bahasa ibu dan bahasa asing 
Bayu Aryanto, Syamsul Hadi, Tatang Hariri, Validitas dan Reliabilitas Tes Melengkapi Wacana pada Penelitian Pragmatik Bahasa Antara (Interlanguage Pragmatics)

sekaligus. Umumnya digunakan untuk mengkomparasikan hasil data antara bahasa ibu dan bahasa asing.

Terlepas dari kontroversi tersebut terkait kekurangan dan keunggulan DCT, dalam penelitian yang terkait dengan komunikasi lintas budaya, DCT masih menjadi instrumen pengambilan data yang paling banyak digunakan oleh peneliti. Bahkan beberapa peneliti ada yang menggunakan DCT dan metode natural (etnografi) secara bersamaan untuk membuktikan sejauh mana data yang diperoleh dari setiap metode tersebut. Beebe dan Cummings (1996) membuat penelitian tentang bagaimana tindak tutur penolakan menggunakan metode WDCT dan metode natural dengan cara berbicara melalui telepon. Salah satu simpulan yang diperoleh dari perbandingan metode pengumpulan data dengan DCT dan etnografi adalah keunggulan dan kekurangan setiap metode tersebut. Baik DCT maupun metode etnografi punya kelemahan dan keunggulan (Beebe dan Cumming, 1996: 80-81).

"DCT do not have the repetitions, the number of turns, the length of responses, the emotional depth, or other features of natural speech, but they do seem to give us a good idea of the stereotypical shape of the speech act."

Pada akhir simpulannya, Beebe dan Cumming (1996: 81) menyatakan sebaiknya peneliti menggunakan lebih dari satu metode untuk mengoleksi data karena setiap metode punya kelemahan dan keunggulannya masing-masing

"....we advocate the comparison of data collected by different data collection procedures, and we urge researchers of interlanguage and native speaker pragmatics to gather data through multiple approaches since each approach has its own strengths and weakness."

Yuan (2002) membuat penelitian tentang tindak tutur pujian dan responnya pada bahasa Cina-Kunming dengan menggunakan DCT dan obeservasi untuk mengilisitasi data. Salah satu tujuan penelitiannya adalah untuk mengetahui realibailitas dan validitas kedua teknik pengumpulan data tersebut. Berikut tabel (1) merupakan perbandingan hasil dari elisitasi data berupa tuturan pujian dari DCT dan obeservasi. 


\begin{tabular}{llll}
\hline & & Natural data (\%) & DCT data (\%) \\
\hline Compliments & $\begin{array}{l}\text { Explisit } \\
\text { complimets }\end{array}$ & 94.53 & 83.10 \\
& $\begin{array}{l}\text { Implisit } \\
\text { compliments }\end{array}$ & 5.47 & 5.71 \\
Non-compliments & $\begin{array}{l}\text { Non-compliments } \\
\text { replies }\end{array}$ & 0 & 7.76 \\
\hline
\end{tabular}

Dari tabel (1) tersebut dapat dilihat bahwa explicit compliment baik dengan observasi dan DCT memiliki prosentase yang sama-sama tinggi pada. Tabel tersebut sama-sama memberikan data bahwa tindak tutur memuji dalam Bahasa CinaKunming didominiasi oleh tindak tutur pujian secara eksplisit (Yuan, 2002: 213). Pada kesimpulannya, Yuan menemukan bahwa dengan menggunakan DCT ada beberapa formula sematik yang tidak ditemukan dalam datanya, tetapi di sisi lain, observasi pun juga ada formula semantik yang tidak muncul. Dengan demikian, keduanya memiliki kelebihan dan kekurangannya masing-masing. Dengan menggunakan DCT semantic formula diperoleh datberupa advice, request, noncompliment dan opt-out, sedangakan pada data observasi tidak ditemukan data seperti itu. Sebaliknya, pada data hasil observasi ditemukan data berupa conversational opener, address term dan appreciation token. Data tuturan pujian dan responnya yang diperoleh dengan metode DCT bersifat monologis, sedangkan dengan observasi selain tuturan pujian, diperoleh pula tuturan pendukungnya seperti pembukaan percakapan, proses negosiasi, dll. Pengendalian instrumen penelitian dapat dilakukan dengan baik pada metode DCT, contohnya pengendalian terhadap gender, usia, bahkan keseimbangan jumlah informan berdasarkan kriteria tertentu bisa dikontrol dengan DCT. Pada akhir simpulannya, Yuan (2002: 2013) menulis:

"....the value of the DCT as a basic tool to get an initial understanding of a speech act/ event in speech community as respondents will tell you how they think a speech act done in their speech community...........Ideally, if there is enough time and manpower, a combination of different data-gathering methods should be used so that the results will complement and compensate for each other"." 
Bayu Aryanto, Syamsul Hadi, Tatang Hariri, Validitas dan Reliabilitas Tes Melengkapi Wacana pada Penelitian Pragmatik Bahasa Antara (Interlanguage Pragmatics)

\section{CONCLUSION/SIMPULAN}

DCT pun mulai banyak perkembangannya dalam rangka penyempurnaan sebagai salah satu instrument pengambilan data. Sebut saja ODCT, yang lebih memiliki kelebihan dibanding WDCT (Eslami, Zohreh R, etc, 2014). ODCT lebih mampu menghasilkan tuturan yang lebih panjang, intonasi, dan faktor ekstralinguistik pun dapat diperoleh.

DCT memang tidak lepas dari kekurangan, tetapi bukan berarti tidak bisa digunakan dalam penelitian pragmatik atau interlaguage pragmatik. Ada baiknya peneliti lebih bersikap bijak bahwa tidak ada instrument pengumpulan data yang paling baik, setiap instrument pengumpulan data pasti memiliki kekurangan dan kelebihannya masing-masing. Data yang bersifat natural bukan satu-satunya patokan untuk menentukan baik atau tidaknya sebuah data/ penelitian (Nurani, 2009: 670).

Penelitian yang baik tidak semata-mata terletak pada keontetikan data, tetapi pada banyak faktor seperti bagaimana pengendalian variabel penelitian yang terkadang dilupakan oleh peneliti sehingga berimbas pada penarikan simpulan yang kurang terukur. Penggunaan lebih dari satu instrument penelitian terutama dalam hal pengambilan data merupakan salah satu alternatif, misal penggunaan DCT dan metode obeservasi seperti yang dilakukan dalam penelitian Yuan (2002), DCT dan metode interview (Althigafi: 2017; Moalla: 2013).

Dengan demikian, DCT dapat dijadikan sebagai salah satu metode pengumpulan data yang dapat dipertanggungjawabkan validitas dan reliabilitasnya apabila sesuai dengan tujuan penelitian yaitu untuk menemukan bentuk realisasi kebahasaan secara masif sehingga dapat menemukan stereotipe realisasi kebahasan dengan topk penelitian tertentu. 


\section{REFERENSI}

Althigafi, Khalid. (2017). Pragmatic Failure in Compliment Responses Among Saudi Speakers of English. Proceeding of $65^{\text {th }}$ ISERD International Conference 2324 Januari.

Beebe, Leslie M; Cumming, Martha Clark. (1996). Natural Speech Act Data Versus Written Questionare data: How Data collection method affect seppec act performance. Speech Acts Across Cultures, pp. 65-86. ed.Susan M Gass dan Joyce Neu. Mouton de Gruyter.

Blum-Kulka, Shoshana., Olshtain, Elite. (1984). Request and Apologies: A CrossCultural Study of Speech Act Realization Patterns (CCSARP). Aplied Linguistics, vol 5 no 3: 196-213.

Clark, Herbert H., Adrian Bangerter. (2004). Changing Ideas About Reference. Experimental Pragmatics. Pp. 25-49. ed. Noveck-Sperber.

Eslami, Zohreh R., Mirzaei, Azizullah. (2014). "Speech Act Data Collection in a Non-Western Context: Oral and Written DCTs in the Persia Language". Iranian Journal of Language Testing. Vol 4 no 1 Maret 2014 pp137-154. Tabaran Institute of Higher Education.

Fukusawa, Emi. (2011). Compliment Responses and Study Abroad. Sophia Junior College Faculty Journal, vol 31, pp. 35-50.

Hirata, Manami. (1993). Home Kotoba he no Hentou (Tanggapan Ungkapan Pujian). Journal of International Student Center. Yokohama International University. Vol 6, pp 38-47.

Jucker, Andreas H. (2009). "Speech Act Research Between Armchair, Field And Laboratory The Case Of Compliments". Journal of Pragmatics 41. Pp 16111635.

Kasper, G.; Dahl, M. (1991). Studies in Second Language Acquisition dalam Research Methods in Interlanguage Pragmatics, pp. 49-69.

Moalla, Asma. (2013). Who Is Responsible for Successful Communication?: Investigating Compliment Responses in Cross-Cultural Communication. Sage Open vol 3 issue 1. https://doi.org/10.1177/2158244012472686

Nurani, Lusia M. (2009). "Methodological Issue Pragmatic Research: Is Discourse Completion Test a Reliable Data Collection Instrument?" Jurnal Sosioteknologi edisi 17 tahun 8, agustus 2009.

Yuan, Yi. (2002). Compliments and Compliments Responses in Kunming Chinese. Pragmatics 12.2: 183-226. 